\title{
Case Report of Secukinumabuse in Psoriatic Arthritis
}

\section{J agdish $\mathbf{R K}^{1 *}$, Shailly ${ }^{2}$ and Bhatnagar $\mathbf{M K}^{3}$}

${ }^{1}$ Consultant Rheumatologist, Kailash and Max Hospital, Noida and Ex. Senior Resident Rheumatology, AIIMS, Delhi, India

${ }^{2}$ TB and Chest Hospital, Government Medical College Patiala, Punjab, India

${ }^{3}$ Santosh Medical College and Hospital Ghaziabad, India and Ex-Director of Lady Hardinge Medical College, New Delhi, India

*Correspondling author: Jagdish RK, Consultant Rheumatologist, Kailash and Max Hospital, Noida and Ex. Senior Resident Rheumatology, AIIMS, Delhi, India

Received: October 12, 2017; Accepted: November 10, 2017; Published: November 17, 2017

\section{Case Report}

A 76 years old male, non smoker, non alcoholic, was diagnosed as psoriatic arthritis 3 years back on the basis of psoriatic skin rash, asymmetrical polyarthritis including distal interphalangeal joints and asymmetric sacroilitis with raised inflammatory markers. He was allergic to sulphasalazine and intolerant to methotrexate. He was given leflunomide $20 \mathrm{mg}$ daily but he did not responded well to it and therefore anti-TNF agent subcutaneous injection etanercept 50 mg weekly was added to it. He responded well and remains stable for about 2.5 years but any attempt to taper antiTNF resulted in recurrence of symptoms and signs, so patient was continued on same dose.

\section{Discussion}

Inspite of regular and adequate dose of etanercept and leflunomide, patient developed skin rash on dorsum of both hands associated with gradually increasing inflammatory type of low back pain and polyarthralgia from last 3 months. On examination his Tender Joint Count (TJC) was 15/68, Swollen Joint Count (SJC) was $0 / 66$,without any deformity, Patient's pain score was $6 / 10$ score, patient global assessment score was $8 / 10$,with increase in CRP-32 mg/L, ESR-41 mm/h, Disease Activity in Psoriatic Arthritis (DAPSA)-32.2(High activity).Secondary anti-TNF Failure was considered and etanercept was stopped. Patient was shifted to subcutaneous injection Secukinumab 300mg every weekly for 4 weeks than monthly, he responded very well within one month, with disappearance of rash and improvement in back pain without any side effect. His DAPSA score significantly improved from 32.2(high activity) to 2.3 (remission) with marked dermatological improvement as shown below in Figure 1-3.

\section{Conclusion}

Even though many patients with psoriatic arthritis benefit from anti-TNF therapy but many do not respond to Anti-TNF agents, therefore unmet needs remain, including an unacceptable side-effect, lack of primary efficacy(primary failure), loss of efficacy(secondary failure), and immunogenicity with these agents in some patients [3-

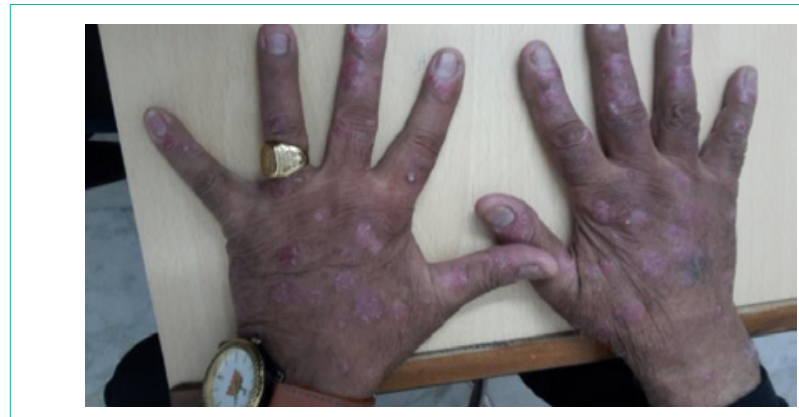

Figure 1: Initial psoriatic skin lesion.

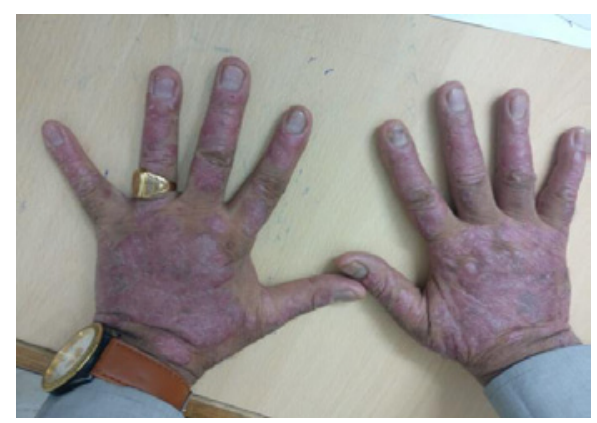

Figure 2: Advanced psoriatic skin lesions.

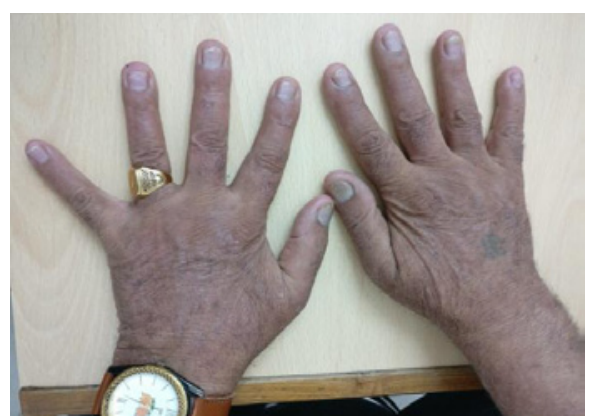

Figure 3: Resolved skin lesion after Secukinumab injection.
Austin J Orthopade \& Rheumatol - Volume 4 Issue 3 - 2017 ISSN: 2472-369X | www.austinpublishinggroup.com

Jagdish et al. (c) All rights are reserved
Citation: Jagdish RK, Shailly and Bhatnagar MK. Case Report of Secukinumabuse in Psoriatic Arthritis. Austin J Orthopade \& Rheumatol. 2017; 4(3): 1059. 
7]. Secukinumab showed efficacy among patients who had received previous anti-TNF therapy and especially in above mentioned situations.

\section{References}

1. Kirkham BW, Kavanaugh A, Reich K. Interleukin-17a: A unique pathway in immune-mediated diseases: psoriasis, psoriatic arthritis and rheumatoid arthritis. Immunology. 2014; 141: 133-142.

2. Ivanov $\mathrm{S}$, linden $\mathrm{A}$. Interleukin-17 as a drug target in human disease. Trends pharmacol sci. 2009; 30: 95-103.

3. MeasePJ, Armstrong AW. Managing patients with psoriatic disease: the diagnosis and pharmacologic treatment of psoriatic arthritis in patients with psoriasis. Drugs. 2014; 74: 423-444.

4. SaadAA, Ashcroft dm, Watson KD, HyrichKL, NoycePR, SymmonsDP, et al. Persistence with anti-tumour necrosis factor therapies in patients with psoriatic arthritis: observational study from the British society of rheumatology biologics register. Arthritis res ther. 2009; 11: 52.

5. Glintborg B, Ostergaard M, Krogh NS, Andersen MD, Tarp U, Loft AG, et al. Clinical response, drug survival, and predictors thereof among 548 patients with psoriatic arthritis who switched tumor necrosis factor a inhibitor therapy: results from the Danish Nationwide Danbio registry. Arthritis rheum. 2013; 65: $1213-1223$

6. Kavanaugh A, Krueger GG, Beutler A, Guzzo C, Zhou B, Dooley LT, et al. Infliximab maintains a high degree of clinical response in patients with active psoriatic arthritis through 1 year of treatment: results from the impact 2 trial. Ann rheum dis. 2007; 66: 498-505.

7. Fagerli KM, Lie E, van der Heijde D, Heiberg MS, Kalstad S, Rødevand E, et al. Switching between TNF inhibitors in psoriatic arthritis: data from the norDMARD study. Ann rheum dis. 2013; 72: 1840-1844.
Austin J Orthopade \& Rheumatol - Volume 4 Issue 3 - 2017 ISSN: 2472-369X | www.austinpublishing group.com Jagdish et al. () All rights are reserved
Citation: Jagdish RK, Shailly and Bhatnagar MK. Case Report of Secukinumabuse in Psoriatic Arthritis. Austin J Orthopade \& Rheumatol. 2017; 4(3): 1059 